\title{
Wood Biomass from the Model Wastewater and Its Fractionation
}

\author{
Galia Shulga, Sanita Vitolina, Julia Brovkina, Brigita Neiberte, Anrijs Verovkins, \\ Maris Pukse, Nikolajs Vedernikovs, \\ Latvian State Institute of Wood Chemistry. Address: 27 Dzerbenes Str., Riga, LV-1006, Latvia
}

\begin{abstract}
The production of veneer in Latvia and many countries of East Europe is accomplished by the hydrothermal treatment of hardwood in special water basins. As a result, formed effluents contain wood-originated pollutants, which are responsible for the enhanced chemical oxygen demand and the intensive colour of the wastewater. Keeping in mind the volume of the polluted effluents formed annually at the Latvian plywood plants, it is very important to extract qualitatively and quantitatively the formed biomass from the effluent. The choose of an effective method of the waste biomass extraction depends on chemical characterisation of the effluent. In this work, for imitating woodworking wastewater, birch sawdust was hydrothermally treated in mild alkaline conditions at $90^{\circ} \mathrm{C}$. The yield of the solid biomass did not exceed $7 \%$ and contained, mainly, hemicelluloses in the polysaccharide form and lignin. The applied instrumental analysis (FTIR-, UV-, Raman spectroscopy) testify the dominant content of hemicelluloses in the obtained biomass. The fractionation of the biomass was performed using concentrated sulphuric acid and ethanol. As the obtained results have shown, the content of lignin, hemicelluloses and water-soluble degraded wood products in the solid biomass corresponded to the following mass ratio: 1.2 /6.7 /1.0, respectively.
\end{abstract}

Keywords - biomass, hemicelluloses, hydrothermal treatment, fractionation, lignin, wastewater.

\section{INTRODUCTION}

Biomass pre-treatment, directed to the destruction of the lignocellulosic matrix, occupies a leading position in lignocellulosic biorefinery for obtaining biofuels and chemicals from cellulose, hemicelluloses and lignin [1-3]. The production of veneer in Latvia and many countries of East Europe is accomplished by the hydrothermal treatment of hardwood in special water basins for 16-18 $\mathrm{h}$ at a temperature lower than $100^{\circ} \mathrm{C}$ and a normal pressure [4]. Depending on the conditions of the hydrothermal treatment, a different yield of wood hydrolysis products occurs due to the hydrolysis of the lignocellulosic matrix [5]. As a result, the formed effluents are polluted with lignin, hemicelluloses, extractives and degraded products from these wood substances, which are responsible for the enhanced chemical oxygen demand and the intensive colour of the wastewater. The chemical indexes of the effluents depend on many factors, namely, the wood species, temperature, $\mathrm{pH}$, etc. Keeping in mind the volume of the polluted effluents formed annually and the zero waste policy for rational use of bioresources, it is very important to extract qualitatively and quantitatively the formed biomass from the effluents for more rational its utilisation than the dilution with pure water to maximum allowable concentrations and then to discharge to natural water basins. It is known that sewage sludge can be used successfully for soil improvement [6], and for producing building materials [7] and sorbents [8]. Evidently, the proper selection of methods for effective extracting of wood biomass from the wood processing effluent is based on its chemical composition and, mainly, on the content of lignin and hemicelluloses.
The aim of the study was to assess the content of lignin- and hemicelluloses-containing fractions in the model solution imitating wastewater of veneer production.

\section{MATERIALS AND METHODS}

Hydrothermal treatment of $60 \mathrm{~g}$ of sawdust $(<1.00$ $\mathrm{mm}$ ) was performed with $0.04 \% \mathrm{NaOH}$ solution at the hydromodulus 1/50 (mass ratio of the oven dry sawdust to water) and a temperature of $90^{\circ} \mathrm{C}$ for $4 \mathrm{~h}$, using a 51 three-neck flask equipped with a return condenser, a thermometer and a stirrer. After hydrolysis, the cooled hydrolysate was separated from the treated sawdust by filtration, and the obtained biomass was dried to a constant mass, at first, at room temperature and then in an oven at $40^{\circ} \mathrm{C}$. The treated sawdust was washed with distilled water to remove the adsorbed hydrolysed degraded products and dried to a constant mass, at first, at $60^{\circ} \mathrm{C}$ and then in an oven at $105^{\circ} \mathrm{C}$. The characteristics of the treated sawdust and the obtained hydrolysate are represented by their average arithmetic values.

The elemental composition of the sawdust and was determined with the Elementar Analysensysteme $\mathrm{GmbH}$ (Germany). Inorganic matter (ash) was found according to Obolenskaya and co-authors [9]. The composition of birch sawdust - lignin, hemicelluloses, cellulose and extractives, before and after hydrolysis, was determined according to analytical chemical procedures. The content of lignin and cellulose was determined by Klason and Kürschner methods, respectively. The content of hemicelluloses was determined as a difference between the content of holocellulose found by treatment with sodium chlorite and glacial acetic acid and cellulose. The content of 190 
extractives represented the sum of the content of the wood substances dissolved in acetone, using a Soxlet extractor, and in boiled water $\left(100^{\circ} \mathrm{C}\right)$ during $3 \mathrm{~h}$ [9]. The found content of cellulose, lignin, hemicelluloses and extractives in the birch wood residue was the following: $40.3 \%, 25.2 \%, 29.2 \%$ and $3.9 \%$, respectively. Biomass component composition was identified by Fourier Transform Infrared (FTIR), Ultraviolet-Visible (UV) and FT Raman spectroscopy. For FTIR- and UV-spectroscopy, a spectrophotometer (Perkin-Elmer Spectrum One, USA) with KBr tablets and a UV-VIS Spectrometer Genesys ${ }^{\mathrm{TM}} 10$ (Thermo, USA) ${ }^{18}$ were employed.

Due to the high fluorescence, for obtaining the spectral characteristics of the biomass, a Multiram FT Raman spectrometer by Bruker with laser power of $125 \mathrm{~mW}$ was used.

Monosugars in the hemicelluloses fraction were determined by a high performance liquid chromatography (HPLC) using a liquid chromatograph (LC) SHIMADZU LC-20A (Shimadzu, Tokyo, Japan) with a refraction index detector. HPLC grade acetonitrile (Sigma-Aldrich, Germany) and water (distillated and deionised) were used for the HPLC analysis. Xylose, arabinose, rhamnose, mannose, glucose and galactose were reference standards. The column configuration was an Alltech Platinum Amino column (100Á 5u, 250x4.6 $\mathrm{mm})$ with a Platinum Amino $\left(\mathrm{NH}_{2}\right)$ guard column $(5 \mathrm{u}$, $7.5 \times 4.6 \mathrm{~mm}$ ). The flow rate was $1.5 \mathrm{ml} / \mathrm{min}$ and the separation was performed at $35^{\circ} \mathrm{C}$. The mobile phase consisted of a degassed filtered mixture of acetonitrile and water $(80: 20 \% \mathrm{v} / \mathrm{v})$. For measuring, a $1.0 \%$ biomass water solution in $0.01 \mathrm{M} \mathrm{NaOH}$ was prepared and filtered through a $0.45 \mu \mathrm{m}$ membrane filter before injection, filed in $1.5 \mathrm{ml}$ bottles with caps and placed in an auto-injector. All samples where tested three times.

$\mathrm{Z}$ potential of the hydrolysate was measured with Malvern Nanosizer SZ (UK). Indexes of COD and colour for the obtained hydrolysate were determined according to ISO 6060:1989 [10] and ISO 7887:1994 [11].

\section{RESULTS AND DISCUSSION}

As shown in Table 1, the obtained hydrolysate was characterised by a moderate alkaline $\mathrm{pH}$ value, a low concentration of dry matter, representing the sum of wood degraded products passing to the hydrolysate, a moderate value of chemical oxygen demand (COD) and a pronounced colour associated with the presence of lignin and lignin-like substances in the hydrolysate .

TABLE 1

PARAMETERS OF THE OBTAINED HYDROLYZATE

\begin{tabular}{|llllll|}
\hline Sample & $\mathrm{pH}$ & $\begin{array}{l}\text { Dry } \\
\text { solids, } \\
\mathrm{g} \mathrm{l}^{-1}\end{array}$ & $\begin{array}{l}\text { Density } \\
\mathrm{kg} \mathrm{m}^{-3}\end{array}$ & $\begin{array}{l}\mathrm{COD}, \\
\mathrm{mg} \mathrm{O} \mathrm{I}^{-}\end{array}$ & $\begin{array}{l}\text { Colour, } \\
\mathrm{mg} \mathrm{Pt} \mathrm{l}^{-}\end{array}$ \\
\hline Hydrolyzate & 9.02 & 1400 & 0.998 & 1285 & 746 \\
\hline
\end{tabular}

The average yield of the solid biomass from the hydrolysate was $7.1 \pm 0.2 \%$ relative to the initial sawdust mass. The yield calculated from the sawdust mass loss was a little higher than that of the dried biomass, which may be associated with a partial adsorption of the formed degraded wood products at the sawdust surface. The defined elemental composition of the dried biomass was the following: $37.75 \% \mathrm{C} ; 4.78 \% \mathrm{H} ; 56.69 \% \mathrm{O} ; 0.30 \% \mathrm{~N} ; 0.14 \% \mathrm{~S}$, $0.34 \%$ of inorganic matter. A SEM image (Fig. 1) characterised the obtained lignocellulosic biomass as an amorphous one without pronounced morphological features.

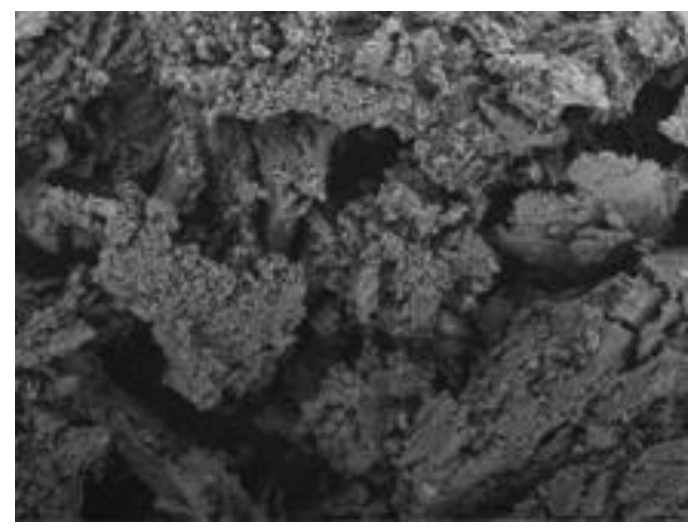

Fig.1. SEM image of the biomass.

The biomass had an enhanced ratio $\mathrm{O} / \mathrm{C}$ close to $1.5 \pm 0.1$ that indicated the presence of a great amount of oxygen-containing groups including hydroxyl, carbonyl and carboxyl groups in the hydrolysed wood products. The zeta potential value of the hydrolysate close to - $30 \mathrm{mv}$ testified the high content of these groups in the biomass. With decreasing $\mathrm{pH}$ to 2.0 , the $\mathrm{Z}$ potential value of the hydrolysate fell to $-10 \mathrm{mv}$, reflecting the decrease in the ionisation degree of the hydroxyl and carboxyl groups in lignin and hemicelluloses fragments.

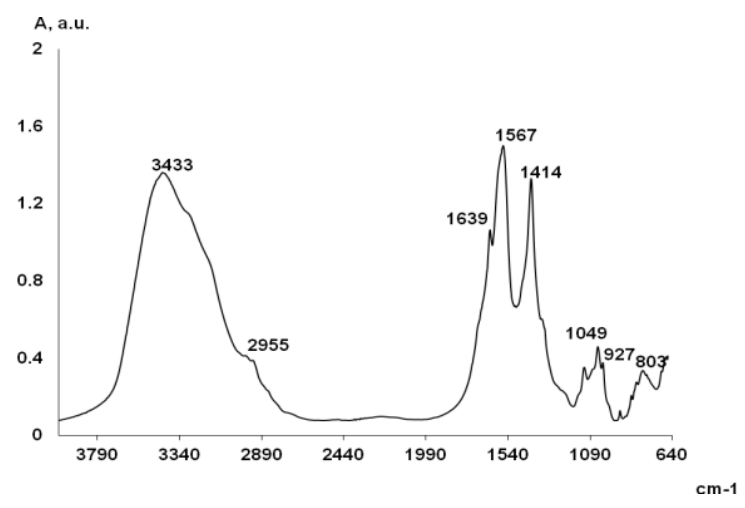

Fig.2. FT-IR spectrum of the biomass.

For fuller characterisation of the chemical composition of the biomass, the FT-IR, UV and FT Raman spectroscopy were applied. The interpretation of the obtained results was based on the literature data concerning the studies of lignin and hemicelluloses by 
the methods [12-14]. According to the FT-IR spectrum of the biomass (Fig. 2), the strong broad band at $3433 \mathrm{~cm}^{-1}$ is attributed to both aromatic and aliphatic hydroxyl groups. The band at $2955 \mathrm{~cm}^{-1}$ is caused by $\mathrm{C}-\mathrm{H}$ stretch vibrations in the methoxyl, methyl and methylene groups present in the aromatic and saccharide structures of the hydrolysed products. The narrow bands at $1639 \mathrm{~cm}^{-1}$ and $1567 \mathrm{~cm}^{-1}$ may be assigned to the presence of ketones, carbonyls and ester groups in the biomass lignin and hemicelluloses. At the same time, in the spectrum, the pronounced bands corresponding to the aromatic skeletal vibrations of lignin structures, namely, $1600 \mathrm{~cm}^{-1}$ and $1505 \mathrm{~cm}^{-1}$ [15] are absent. The presence of lignin structures in the biomass is testified by the absorbance at $1414 \mathrm{~cm}^{-1}$, assigned to skeletal vibrations and $\mathrm{C}=\mathrm{O}$ group stretching in the syringyl and guaiacyl aromatic rings. The $\mathrm{CH}_{2}$ deformation vibrations appear at 1351 $\mathrm{cm}^{-1}$ and may be caused by both lignin and hemicelluloses structures. The bands in the region of 1115-803 $\mathrm{cm}^{-1}$ are typical for hemicelluloses. This region contains $\mathrm{C}-\mathrm{C}$ ring vibrations, overlapped with the stretching vibrations of $\mathrm{C}-\mathrm{OH}$ side groups and the $\mathrm{C}-\mathrm{O}-\mathrm{C}$ glucosidic band vibrations. The band at 1115 $\mathrm{cm}^{-1}$ may be caused by the presence of pectin. The band at $1047 \mathrm{~cm}^{-1}$ is attributed to the $\mathrm{C}-\mathrm{O}-\mathrm{C}$ stretching in glucosidic linkages, which is typical for xylan. The small bands at $927 \mathrm{~cm}^{-1}$ and $803 \mathrm{~cm}^{-1}$ are characteristic of the $\beta$-glucosidic bonds between the sugars units.

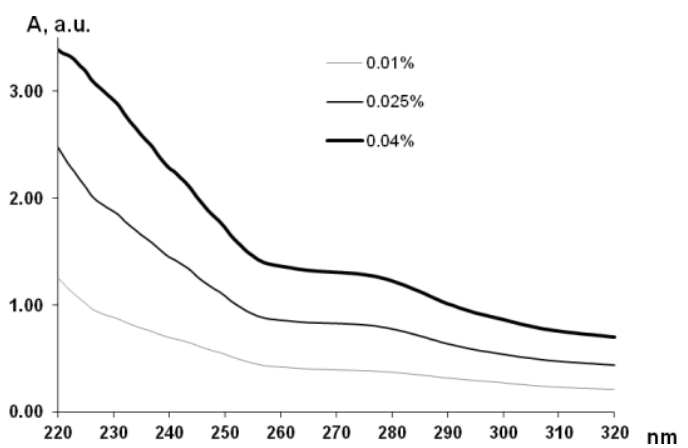

Fig. 3. UV spectra of the biomass water solutions at $\mathrm{pH} 9.0$.

Fig. 3 shows UV-spectra of $0.01-0.04 \%$ solutions of the biomass with $\mathrm{pH}$ 9.0. The obtained spectra testify the presence of aromatic fragments in the biomass, namely, the absorption at $280 \mathrm{~nm}$ is typical for lignin. At the same time, the relatively low value of the calculated extinction coefficient $\left(3.89 \mathrm{lg}^{-1} \mathrm{~cm}^{-1}\right)$ at this band indicates the dominant content of the nonaromatic structure in the dried biomass.

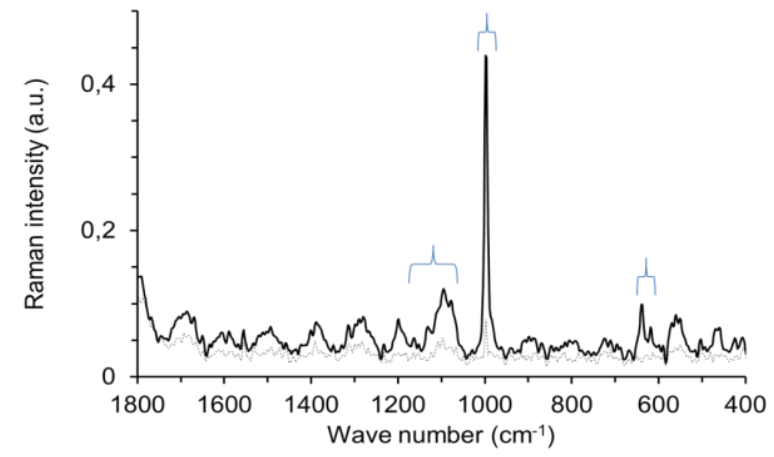

Fig. 4. FT Raman spectrum of the biomass.

This suggestion confirms the obtained FT Raman spectrum of the lignocellulosic biomass presented in Fig. 4. According to the known assignment of the vibration bands in FT Raman lignocellulosic materials [16], the strong pronounced bands observed in the interval of $1200-1000 \mathrm{~cm}^{-1}$ may be assigned to $\mathrm{C}-\mathrm{C}$ an $\mathrm{C}-\mathrm{O}$ stretching vibrations in hemicelluloses. At the same time, less manifested and weaker bands in the interval of $550-630 \mathrm{~cm}^{-1}$ may testify the presence of aromatic structures of lignin in the obtained biomass.

To fractionate the lignocellulosic biomass and calculate the content of lignin and hemicelluloses therein, the precipitation of the hydrolysate with concentrated sulphuric acid, with the following treatment of the formed filtrate with ethanol, according to Liu and co-authors [17] was employed. The scheme of the applied fractionation is given in Fig. 5. For the fractionation, the biomass dried at room temperature was dissolved in $0.1 \mathrm{M} \mathrm{NaOH}$ for obtaining $50 \mathrm{ml}$ of a $35 \%$ biomass solution. The concentrated hydrolysate was, at first, acidified with $20 \%$ sulphuric acid to a $\mathrm{pH}$ of 2.0 at room temperature with the following filtration and centrifugation of the obtained suspension for separating the lignincontaining fraction. The lignin precipitate was washed with distilled water to $\mathrm{pH} 5.5$ and dried in an oven at $40^{\circ} \mathrm{C}$. Anhydrous ethanol was added to the obtained filtrate at the volumetric ratio of ethanol/filtrate close to 4. After addition of anhydrous ethanol, the hemicelluloses-containing fraction precipitated and then was isolated by centrifugation, washed with the ethanol and dried in an oven at $40^{\circ} \mathrm{C}$. The content of hemicelluloses- and lignin-containing fractions in the biomass was assessed from the masses of the obtained dried precipitates. 

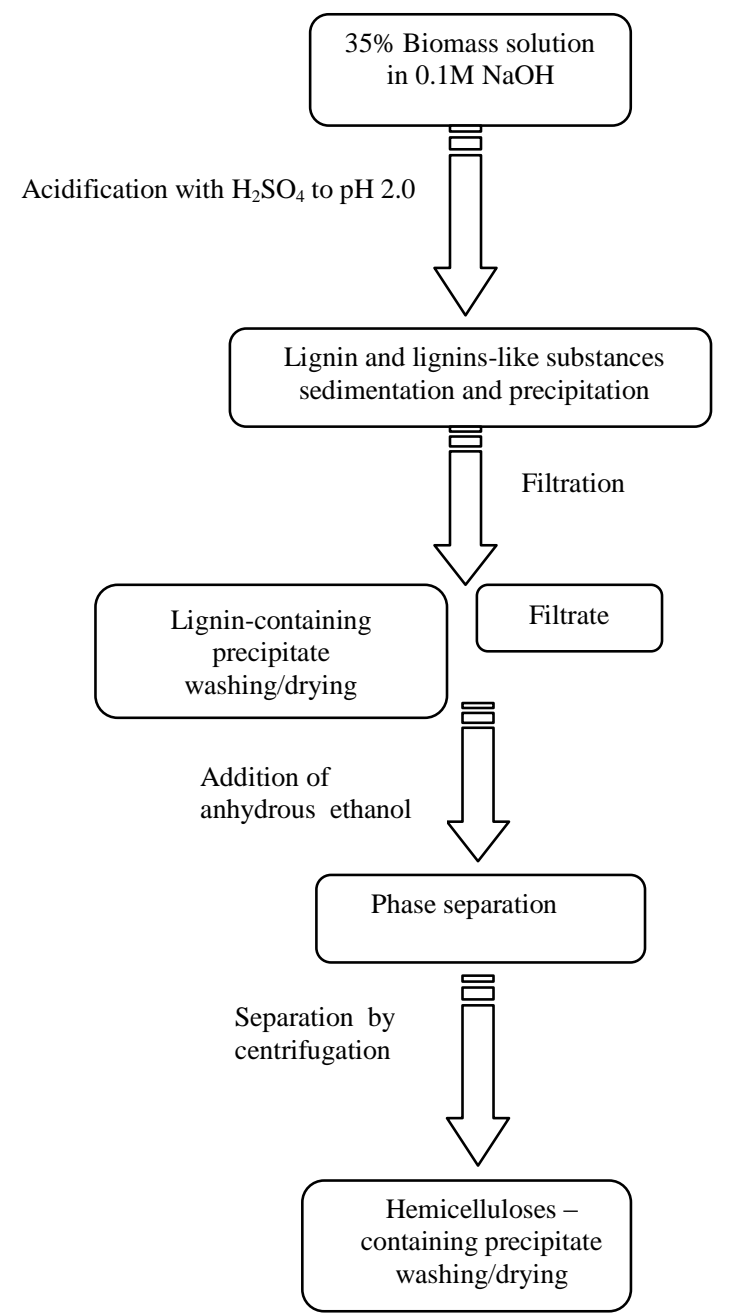

Fig. 5. Scheme of biomass fractionation

The FTIR spectrum of the isolated lignin and the isolated hemicelluloses are given in Fig. 6. In FTIR spectrum of lignin, typical bands can be seen, which are common for hardwood lignins, namely, a band at $1323 \mathrm{~cm}^{-1}$ and that at $821 \mathrm{~cm}^{-1}$ are assigned to syringyl rings. For FTIR spectrum of the isolated hemicelluloses, typical absorbance bands of glucosidic linkages in the $1200-800 \mathrm{~cm}^{-1}$ are observed.

The obtained results of the biomass fractionation showed that the content of the lignin and hemicelluloses fractions in the solid biomass corresponded to $13.5 \%$ and $75.2 \%$, respectively. At the same time, the low molecular products of the lignocellulosic matrix destruction that were not able to be

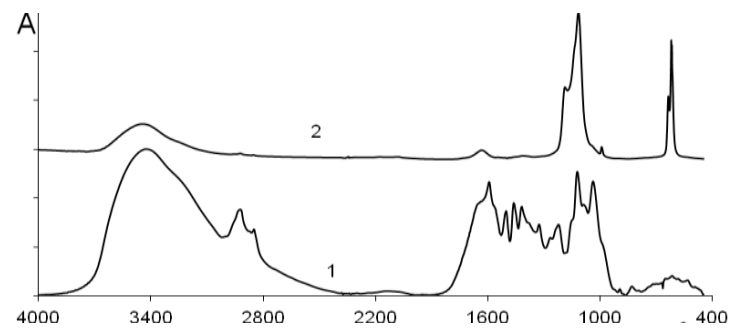

Fig. 6. FTIR spectra of biomass components: lignin (1), hemicelluloses (2). precipitated by this procedure occupied $11.3 \%$ of the solid biomass. The measuring of the content of water-soluble lignin [9] in the filtrate obtained after the Klason lignin extraction corresponded to $5.89 \%$, and the total content of lignin (Klason and watersoluble) in the biomass was $10.9 \%$. As the obtained results have shown, the content of lignin, hemicelluloses and water-soluble degraded wood products in the solid biomass corresponded to the following mass ratio: 1.2/6.7/1.0, respectively.

TABLE 2.

WOOD COMPONENT COMPOSITION OF BIRCH SAWDUST BEFORE AND AFTER THE HYDROLYSIS

\begin{tabular}{lllll}
\hline Sample & $\begin{array}{l}\text { Holo- } \\
\text { cellulose, } \\
\%\end{array}$ & $\begin{array}{l}\text { Cellulose, } \\
\%\end{array}$ & $\begin{array}{l}\text { Hemi- } \\
\text { cellulose } \\
\%\end{array}$ & $\begin{array}{l}\text { Lignin, } \\
\%\end{array}$ \\
\hline $\begin{array}{l}\text { Untreat } \\
\text { ed }\end{array}$ & 68.5 & 40.3 & 28.2 & 25.2 \\
\hline Treated & 70.4 & 46.8 & 23.6 & 25.1 \\
\hline
\end{tabular}

Simultaneously, the changes in the wood composition of birch sawdust due to its hydrolysis were assessed. According to the results listed in Table 2 , the main changes in the wood composition caused by the hydrolysis took place for cellulose, i.e., its content increased by $6.5 \%$ and hemicelluloses, i.e., their content decreased by $5.6 \%$, while the content of lignin diminished by only $0.1 \%$. It is reasonable to assume that the gain in the cellulose content and the negligible alteration in the lignin content in the pretreated lignocellulosic matrix were associated with the notable losses of hemicelluloses and water-soluble extractives during the hydrothermal treatment.

The chemical and morphological characteristics of the precipitated birch lignin were studied by Shulga and co-authors [18]. Hemicelluloses in the biomass were identified by a liquid chromatograph. The identifying HPLC analysis (Fig. 7) testified the presence of xylose, mannose, arabinose, rhamnose and glucose monomers in a $1.0 \%$ birch hydrolysate $\mathrm{mV}$

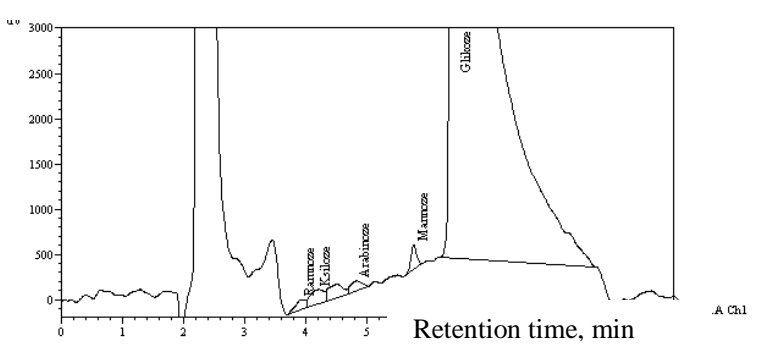

Fig. 7. HLPC chromatogram of a $1 \%$ biomass aqueous solution in $0.01 \mathrm{M} \mathrm{NaOH}$.

The obtained quantitative data analysis showed that the content of the first four sugars in the obtained hydrolysate was comparatively low and did not exceed $0.1 \%$. This means that the hemicelluloses in the hydrolysate are represented mainly by polysaccharides. At the same time, the glucose content 
in the hydrolysate was higher and close to $0.4 \%$, which may be associated with the features of the birch lignocellulosic matrix degradation during the hydrolysis.

\section{CONCLUSION}

For imitating woodworking wastewater, birch sawdust was hydrothermally treated in mild alkaline conditions at $90^{\circ} \mathrm{C}$. The yield of the solid biomass did not exceed $7 \%$ and contained, mainly, hemicelluloses in the polysaccharide form and lignin. The applied instrumental analysis (FTIR-, UV-, Raman spectroscopy) testify the dominant content of hemicelluloses in the obtained biomass. The study of the biomass with a high performance liquid chromatograph identified, along with xylose, glucose and mannose, also arabinose and rhamnose. The fractionation of the biomass was performed using concentrated sulphuric acid and ethanol. As the obtained results have shown, the content of lignin, hemicelluloses and water-soluble degraded wood products in the solid biomass corresponded to the following mass ratio: $1.2 / 6.7 / 1.0$, respectively.

\section{$\mathrm{V}$ ACKNOWLEDGMENTS}

The authors are grateful to the Latvian Council of Science and the Latvian Ministry of Economics for the financial support of the grant No.09.1610c and the National Research Programme VPP-5.

\section{REFERENCES}

[1] Brodeur G., Yau E., Badal K. J., Collier J., Ramachandran B. Ramakrishnan S. Chemical and physicochemical pretreatment of lignocellulosic biomass: a review. Enzyme Res., Article ID 787532. 2011, $17 \mathrm{pp}$.

[2] Mtui G.Y.S. Recent advances in pretreatment of lignocellulosic wastes and production of value added products. African J. Biotechnol., 8. 2009, pp. 1398-1415 .
[3] Yang B., Wyman C.E. Pretreatment: the key to unlocking low-cost cellulosic ethanol. Biofuel. Bioprod. Bior., 2. 2008, pp. 26-40.

[4] Permission of polluting activities for B category Nr. RE12IB0006. Rezekne Regional Environmental Governance. Ltd RSEZ Verems. 2012, 82 pp.

[5] Fengel D., Wegener G. Wood - Chemistry, Ultrastructure, Reactions. De Gruyter, Berlin, 1984.

[6] Lakhdar A., Scelza R., Scotti R. The effect of compost and sewage sludge on soil biologic activities in salt affected soil. R.C. Suelo Nutr. Veg., 10. 2010, pp. 40-47.

[7] Lin D., Weng C. Use of sewage sludge ash as brick material. J. Environ. Eng., 127. 2001, pp. 922-928.

[8] Rio S., Le Coq L., Faur C., Le Cloirec P. Production of porous carbonaceous adsorbent from physical activation of sewage sludge: application to wastewater treatment. Water Sci. Technol., 53. 2006, pp. 237-244.

[9] Obolenskaya A.V., Elnitskay Z.P., Leonovich A.A. Laboratory Manual on Wood and Cellulose Chemistry. Ecologia, Moscow, 1991.

[10] ISO 6060:1989. Water quality - Determination of Chemical Oxygen Demand.

[11] ISO 7887:1994. Water quality - Examination and Determination of Colour.

[12] Sanchez S., Egues I., Llano-Ponte R., Labidi J. Acid- and base- catalized hydrolyses of corn stalk. Bioresources 6 . 2011, pp. 1830-1842.

[13] Fang J.M., Sun R.C., Tomkinson J. Isolation and characterisation of hemicelluloses and cellulose from rye straw by alkaline peroxide extraction. Cellulose 7. 2000, pp. 87-107.

[14] Kačurakova M., Capek P., Sasinkova V., Wellner N., Ebringerova A. FT-IR study of plant cell wall model compounds: pectic polysaccharides and hemicelluloses. Carbohyd. Polym., 43. 2000, pp. 195-203.

[15] Faix O. Fourier Transform Infrared Spectroscopy. In: Methods in Lignin Chemistry. Eds. Lin S.Y., Dence C.W. Springer-Verlag, Berlin. 1992, pp. 233-241.

[16] Agarwal U.P. An overview of Raman Spectroscopy as applied to Lignocellulosic Materials. In: Advances in Lignocellulosic Characterization. Chapter 9. Eds. Hu T., Blackwell Publishing, USA. 2008, pp. 201-225.

[17] Liu Z., Ni Y., Fatehi P., Saeed A. Isolation and cationization of hemicelluloses from pre-hydrolysis liquor of kraft-based dissolving pulp production process. Biomass Bioenerg., 35. 2011, pp. 1789-1796.

[18] Shulga G., Vitolina S., Shakels V., Belkova L., Cazacu G., Vasile C., Nita L. Lignin separated from the hydrolyzate of hydrothermal treatment of birch wood and its surface properties. Cellulose Chem. Technol., 46. 2012, pp. 307-318. 